\title{
Application of parylene-coated quartz crystal microbalance for on-line real-time detection of microbial populations
}

\author{
Hsieh-Cheng Han ${ }^{\mathrm{a}}$, Ying-Rong Chang ${ }^{\mathrm{a}}$, Wen-Lin Hsu ${ }^{\mathrm{b}, * *, 1}$, Chien-Yuan Chen ${ }^{\mathrm{a}, \mathrm{b}, *, 1}$ \\ a Department of Biochemical Science and Technology and Institute of Microbiology and Biochemistry, National Taiwan University, Taipei, \\ Taiwan, $R O C$ \\ b Department of Radiation Oncology, Buddhist Tzu Chi General Hospital, Taichung Branch, Taichung, Taiwan, ROC
}

\section{A R T I C L E I N F O}

\section{Article history:}

Received 12 May 2008

Received in revised form 2 July 2008

Accepted 15 July 2008

Available online 29 July 2008

\section{Keywords:}

Quartz crystal microbalance

Parylene

pQCM sensor

E. coli

Mass loading

Fermentation process

\begin{abstract}
A B S T R A C T
A novel technique of applying a quartz crystal microbalance (QCM) sensor to the on-line real-time detection of microbial populations is described. The $p \mathrm{QCM}$ sensor was fabricated by depositing di-para-xylene (parylene) over the entire surface of a QCM sensor through a chemical vapor deposition (CVD) process. An electrically insulated film of parylene on the QCM sensor enabled the operation of the sensor in the liquid environment, and the resonance frequency of the $p Q C M$ sensor set in the medium of a cultivation flask shifted in response to the microbial population.

The effects of $\mathrm{pH}$, conductivity, and viscosity of the medium on the frequency shift of the $\mathrm{QQCM}$ sensor were investigated. Ignorable responses (less than $1 \%$ at $10^{3}$ cells) were obtained during an incubation cycle.

The detection limit of the $p Q C M$ sensor was identified as $10^{2}$ cells $\mathrm{ml}^{-1}$ with a frequency shift of around $2 \times 10^{3} \mathrm{~Hz}$. The cell numbers of Escherichia coli cultivated in both the YEM medium and whole milk were detected. A satisfactory correlation $\left(r^{2}=0.95\right)$ was obtained between the cell number and the response of the $p Q C M$ sensor.

Experimental results suggest that the $p Q C M$ described here is applicable to the continuous long-term detection of microbial populations during a fermentation process.
\end{abstract}

(c) 2008 Elsevier B.V. All rights reserved.

\section{Introduction}

The presence of bacteria in food, water, environmental samples, etc., could be monitored by measuring the physicochemical changes caused by bacterial growth or metabolism. Escherichia coli is an organism that commonly lives commensally in gastrointestinal tracts. It is one of the most important pathogenic bacteria capable of contaminating foodstuffs, thereby causing food poisoning; it can also cause enteric infections in humans, with severe and fatal consequences (Kosorok et al., 1998; Oliver et al., 2003). The cost of such contamination to the dairy food industry is associated with loss of yield, cost of discarded food, waste of herdsmen's time, and extra services of culling (Miller et al., 1993).

\footnotetext{
* Corresponding author at: Department of Biochemical Science and Technology and Institute of Microbiology and Biochemistry, National Taiwan University, 1, Sec. 4 Roosevelt Road, Taipei, Taiwan, ROC. Tel.: +886 2 33664449; fax: +8862 23661696 .

** Corresponding author. Tel.: +886 4 36060666; fax: +886 436020123.

E-mail addresses: chenyuan@ntu.edu.tw, spacefly@mail2000.com.tw (C.-Y. Chen).

${ }^{1}$ These authors contributed equally.
}

Various techniques have been developed for the detection of $E$. coli, such as Gram-staining analysis, enzyme-linked immune-sorbent assay (ELISA) (Louis et al., 1998; Kim et al., 2004), polymerase chain reaction (Xu et al., 2004), and automated detection of food-borne pathogens (Oberst et al., 1998; Sharma et al., 1999), all having been developed to improve upon the currently available technology (conductivity monitoring).

Recently, a variety of biosensors used in the analysis of molecular recognition have been developed for the detection of pathogenic bacteria. These biosensors are a unique combination of a receptor for molecular recognition and a transducer for converting the interaction information into an electrical signal.

For example, in robotic milking systems, mastitis detection is carried out by placing electrodes in the milking system in order to detect changes in the conductivity of milk (electrical conductivity). But, in mastitis detection, there is no evidence to suggest that it is possible to detect all types of changes by a conductivity assay (De Mol and Ouweltjes, 2000). Additional drawbacks of conductivity measurements have been reported such as the failure to detect mastitis caused by Streptococcus uberis and a high number of false positive results (Hillerton and Walton, 1991; Milner et al., 
1996). Furthermore, electrical conductance methods employed for the same purpose are unable to yield an acceptable specificity or sensitivity of clinical, food, or environmental contaminations (Toby et al., 2007).

Surface plasmon resonance (SPR) immunosensors offer high sensitivity, selectivity, speed, and reliability in analyses. However, their use for the on-line monitoring of bacteria involves high expenditure and difficulties in their miniaturization (Mullett et al., 2000; Shankaran et al., 2007).

A quartz crystal microbalance (QCM)-based technique is favorable over SPR and impedance technology from the viewpoints of system miniaturization and cost. Following the theory of Sauerbrey, the observed decrease in frequency should be proportional to the change in the mass of the quartz resonator (Sauerbrey, 1959).

Furthermore, researchers have developed immunosensors exploiting QCM as the biosensor for the detection of important bacteria (Fengjiao et al., 1994; Noel and Topart, 1994; Ben-Dov et al., 1997; Spangler and Tyler, 1999; Spangler et al., 2001), including E. coli (Park et al., 2000; Spangler et al., 2001). They can also be used to detect precise changes in the oscillation frequency and energy dissipation, which occur when membranes or molecules bind to an oscillating quartz crystal (Keeneth, 2001; Cavic et al., 1999). In a recent research conducted on the hepatitis $C$ virus, it was shown that the real-time kinetics of the interactions occurring on the lipid bilayer is derived from the cells (Cho et al., 2007).

Cell proliferation has been reported from the adherence of cells onto the QCM gold electrode; cell proliferation can be used to monitor cell-cycle-related viscoelasticity (Alessandrini et al., 2006). Moreover, cell fibrillations induce a change in the viscoelastic properties of the QCM during multilayered amyloid deposition onto the electrode surface (Hovgaard et al., 2007).

Classical QCM technology involves studies that require the removal of samples from the liquid environment of a fermentor by pumping out samples; subsequently, investigations are carried out by using spectrophotometers, QCM microscopes, etc., as well as conductive analyses. These removal methodologies can aid in the precise removal of a small-volume sample from a bioreactor by using a fluid control pump; however, these methodologies are plagued with problems induced by sample removal or the rinsing process, which can alter microorganisms. These technologies are not suitable for large-scale experiments. Besides, QCMs are fabricated by coating a metal electrode on both sides such that when they are used in liquids, the electrodes are shortened. This in turn would decrease the effective surface due to the above-mentioned reasons.

Parylene is biocompatible, hydrophobic, and highly transparent; it does not have pinholes and it lowers dynamic capacity and inductance. Furthermore, it offers high resistance against acids, organic solvents, and inorganic solvents, and it is an insulator.

In this paper, we present a QCM biosensor device that is modified by parylene. This device is referred to as $p Q C M$; it can potentially be used for an organic transfer in medical treatment. The $p Q C M$ sensor can directly analyze the microorganisms in a fermentor, and the two electrodes aid in more mass loading.

In addition, it may prevent any risk posed by toxins produced due to surface modification. $p Q C M s$ are inexpensive and can easily be used for on-line tests performed for contamination determination. The fabrication details and performance of the device are provided later in this manuscript. The application of the device is demonstrated, and the results are discussed at the end of the manuscript.

\section{Materials and methods}

\subsection{Sensor fabrication and characterization}

Parylene coating allows $E$. coli to deposit but not to conjugate on the sensor surface. This specificity of parylene coating thus efficiently helps to protect electrodes for extended use when compared to other rough ways (such as piranha solution) to remove E. coli. Even more, it provides more chemical stability.

The base of the $p Q C M$ is a polished surface, which is a $10-\mathrm{MHz}$ AT-cut quartz crystal (Taitien Electronics Co., Ltd., Taiwan) with gold electrodes that are $8 \mathrm{~mm}$ in diameter; the surface roughness of the electrodes is approximately $2 \mathrm{~nm}$. The device is pretreated by piranha solution at $60^{\circ} \mathrm{C}$ for $5 \mathrm{~min}$ and rinsed by deionized water; then, it is dried in a stream of nitrogen, treated with $\mathrm{O}_{2}$ plasma, and placed in a deposition chamber in which it is coated with parylene (PDS-2010, Samco, USA). The thickness of the parylene film is approximately $1 \mu \mathrm{m}$ at room temperature, and the pressure in the chamber is -30 Torr; the thickness of the parylene film is investigated by an $\alpha$-stepper meter (SE4000, Kosaka, Japan). We also investigated the following characteristics related to the $p \mathrm{QCM}$ : hydrophobicity, surface roughness, mass loading of liquid, the effect of temperature, and the effect of $\mathrm{pH}$.

The hydrophobicity of parylene is investigated by an instrument for measuring the surface contact angle (FTA 125, First Ten Angstroms, USA); the water contact angle is found to be approximately about $110^{\circ}$, and the roughness, measured by an atomic force microscope (AFM; XE-100 SPM, Park Systems Corp., Korea) is found to be approximately $10 \mathrm{~nm}$.

The frequency losses are affected by the thickness of parylene coating: $0.0297 \mathrm{MHz}$ for $0.1 \mu \mathrm{m}, 0.030 \mathrm{MHz}$ for $0.5 \mu \mathrm{m}, 0.048 \mathrm{MHz}$ for $1 \mu \mathrm{m}$, and $0.111 \mathrm{MHz}$ for $2 \mu \mathrm{m}$. The increase of coating thickness leads to the increase of mass loading and the decrease of frequency shifts, matching exactly Sauerbrey equation. There is no significant change in terms of the quality factor when QCM is modified as pQCM (when coating thickness reaches $1 \mu \mathrm{m}$ ), investigated by an Impedance Analyzer.

\subsection{Data acquisition system and $p Q C M$ measuring cell}

A frequency counter (HP 5313A) and a Colpitts oscillator operating near the first harmonic are used to measure the frequency shift of the $p Q C M$, as shown in Fig. 1a. All systems were developed in our laboratory (Chou et al., 2002a,b; Chang et al., 2003).

We constructed an aqueous measuring cell, which was a $p Q C M$ device mounted on a cell cultivation flask $\left(25-\mathrm{cm}^{2}\right.$ tissue culture flask, USA); the entire $p$ QCM device was immersed into a liquid. The effect of temperature on the oscillation frequency was determined for the $p \mathrm{QCM}$ crystal. The temperature coefficient for an AT-cut quartz crystal at $25^{\circ} \mathrm{C}$ was approximately $0.5 \mathrm{ppm} /{ }^{\circ} \mathrm{C}$; after being coated with the parylene film, the temperature coefficient increased to $10 \mathrm{ppm} /{ }^{\circ} \mathrm{C}$.

To determine the sensitivity of the $p Q C M$ sensor, a dilution experiment was performed for various quantities of $E$. coli cells; sodium chloride and BSA were detected on the surface. When the concentration of $E$. coli suspension was successfully adjusted from $10^{1}$ to $10^{4}$ cells $\mathrm{ml}^{-1}$ (cells counted by microscope), $40 \mathrm{ml}$ were directly injected into the measuring cell to detect the frequency shifts after the interval of $5 \mathrm{~min}$. A slope of $4 \mathrm{~Hz} / \mathrm{mm}^{2} \mathrm{ng}^{-1}$ was used to compute accumulated dry mass of the detected sodium chloride under air conditions, and a slope of $14 \mathrm{~Hz} / \mathrm{mm}^{2} \mathrm{ng}^{-1}$ was used to compute the aqueous mass loading of the detected BSA under liquid conditions $(40 \mathrm{ml})$.

We have shown that the $\mathrm{pQCM}$ system has good sensitivity, similar to that of a conventional QCM. In a recent research on the QCM, 

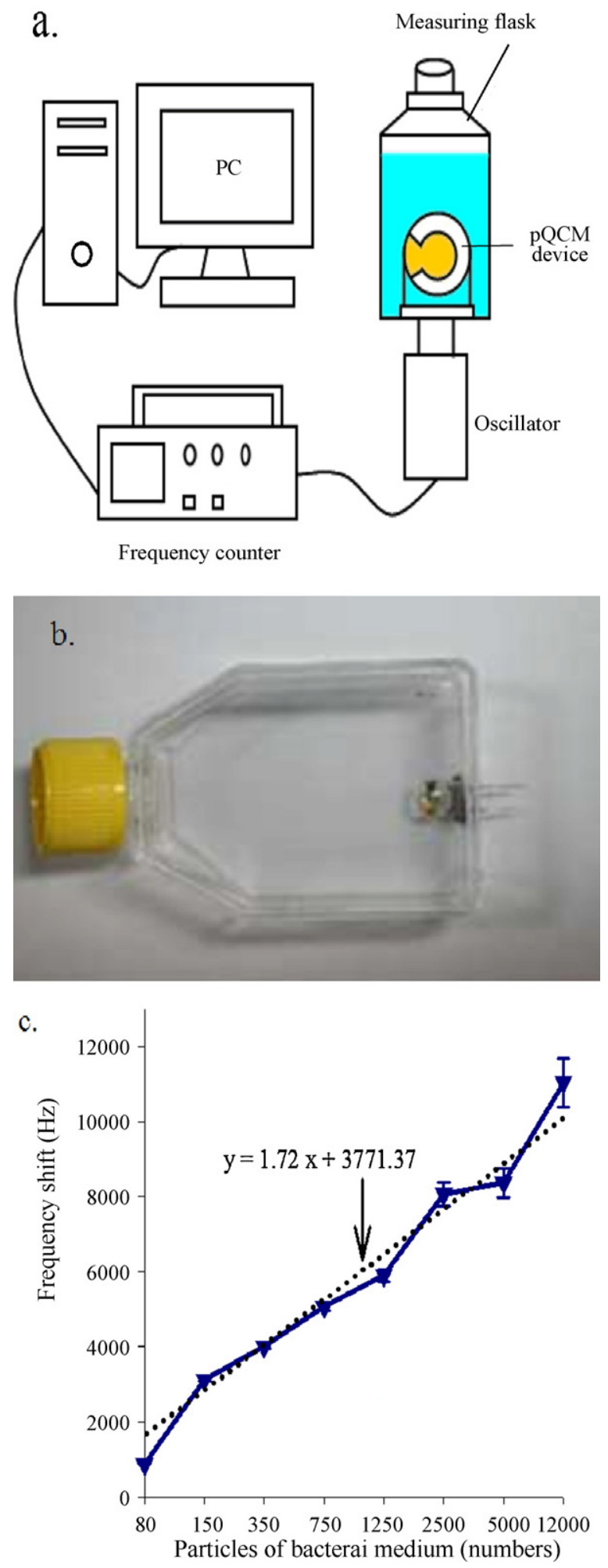

Fig. 1. (a) $p Q C M$ device mounted on a $25 \mathrm{~T}$ flask. The flask is sealed with epoxy and wired to the oscillator that is connected in series to a radio frequency counter; data is acquired by a PC. (b) Photograph of a working system. (c) The sensitivity curve of E. coli cells. it has been found that the sensitivity of the QCM for the detection of bacteria in an assay time of $60 \mathrm{~min}$ is approximately $10^{2} \mathrm{cfu} \mathrm{ml}^{-1}$ (Cooper and Singleton, 2003).

\subsection{Bacteria culture and experimental procedure}

The E. coli clone EPI300 was obtained from a stock at $-70^{\circ} \mathrm{C}$ in nutrient broth with $25 \%$ glycerol. The $E$. coli was routinely cultured in a YEM growth medium containing $2.5 \mathrm{~g}$ yeast extract (Difco, MD, USA), $0.1 \mathrm{~g}$ sodium chloride (Amresco, Ohio, USA), $2.5 \mathrm{~g}$ bacto-peptone (Sigma, St. Louis, MO, USA), $2.5 \mathrm{~g}$ bactotryptone (Becton, Dickinson and Co., France), $10 \mathrm{~g}$ manitol (Nacalai Tesque, Inc., Japan), $0.2 \mathrm{~g}$ magnesium sulfate heptahydrate (Nacalai Tesque, Inc., Japan), $0.5 \mathrm{~g}$ potassium phosphate, and monobasic (Hayashi Pure Chemical Inc., Japan) in $18 \mathrm{M} \Omega \mathrm{cm}^{-1}$ water. The final solution was sterilized using a filter with a pore size of $0.2 \mu \mathrm{m}$.

The first step was to pre-culture E. coli on solid plate and then to transfer a single colony to liquid YEM medium of $40 \mathrm{ml}$ for incubation. After $6 \mathrm{~h}, 1 \mathrm{ml}$ of $E$. coli suspension was taken to detect its concentration. When its $\mathrm{OD}_{600}$ had reached 0.8 , another $1 \mathrm{ml}$ was taken to the process of serial dilution and cell counting by microscope. When the concentration of E. coli suspension was successfully adjusted to $5 \times 10^{3}$ cells $\mathrm{ml}^{-1}$ (cells counted by microscope), $1 \mathrm{ml}$ of it was inoculated into the measuring cell which was first sterilized by $70 \%$ ethanol, then filled with YEM or milk medium of $39 \mathrm{ml}$ and finally injected with counted $E$. coli for incubation. At the interval of $3 \mathrm{~h}$, the measuring cell was taken out from the oscillating incubator to detect frequency shifts. Before the detection, another extra $5 \mathrm{~min}$ was required to reduce the vibration of the liquid medium to maintain the cells' homogeneity.

All cell calibration growth curves were measured by a spectrophotometer (U-2000, Hitachi, Japan). We developed a protocol for monitoring the behavior of proliferating bacteria over a long period of time (1-2 days per assay); the monitoring was repeated more than five times. Test samples were incubated at $30^{\circ} \mathrm{C}$ for all the experiments and placed inside a shaking incubator rotating at $200 \mathrm{rpm}$; the flask was maintained at $30^{\circ} \mathrm{C}$ in dark.

\subsection{1. $p H$ value and conductivity of YEM/milk medium}

At intervals of $3 \mathrm{~h}$, we collected $1 \mathrm{ml}$ of each solution containing bacteria. Each sample was centrifuged at $4000 \mathrm{rpm}$ for $15 \mathrm{~min}$. Then, the supernatant of the cultured medium samples was collected and the $\mathrm{pH}$ values were measured at a constant temperature of $25^{\circ} \mathrm{C}$.

The conductivities of the $1 \mathrm{ml} \mathrm{YEM-pQCM}$ and milk- $p Q C M$ samples were monitored at $3 \mathrm{~h}$ intervals for $24 \mathrm{~h}$. The responses of the measured conductance were recorded according to the peak, in millisiemens per centimeter $\left(\mathrm{mS} \mathrm{cm}^{-1}\right)$ by a TDScan 20, (Omega Scientific, USA) at $25^{\circ} \mathrm{C}$ at a depth of $1.5 \mathrm{~cm}$ below the liquid surface.

\subsubsection{Viscosity of YEM/milk medium}

For determining the viscosity of the medium under investigation, we calibrated our nutrient mediums, i.e., YEM and milk samples, with glycerol-water mixtures of known density and viscosity (according to Weast, 1984).

The viscosities of the YEM, milk, and glycerol-water mixtures were measured using an LVT-type viscometer with a needle indicator, manufactured by Brookfield, USA. The LV4 probe was adjusted at $60 \mathrm{rpm}$ and at a depth of $10 \mathrm{~cm}$ below the liquid surface. All measured viscosity responses were recorded according to the peak in centipoises (cps) at $25^{\circ} \mathrm{C}$. Both types of samples were monitored every $3 \mathrm{~h}$ and the monitoring was repeated more than five times. 


\subsection{3. $p Q C M$ sensor reusability}

After every measurement, the waste formed in the medium was thrown out. Then, the measuring flasks were gently rinsed by $\mathrm{ddH}_{2} \mathrm{O}$ and dried with a stream of nitrogen, followed by the measurement of the fundamental frequencies of the $p \mathrm{QCM}$ system.

\section{Results and discussion}

\subsection{Detection of bacterial population}

By setting the detection range as $10^{1}$ to $10^{4}$ cells ml- ${ }^{-1}$ (as shown in Fig. 1c), a linear sensitivity on the logarithmic value of the E. coli concentration could be observed from $10^{2}$ to $10^{4}$ cells $\mathrm{ml}^{-1}$, with a detection limit of $10^{2}$ cells $\mathrm{ml}^{-1}\left(r^{2}=0.95\right)$. The frequency shift is approximately $2 \mathrm{kHz}$.

Fig. 2 shows the frequency shifts of the YEM bacterial medium and milk bacterial medium; the growth curve of the cell concentra-

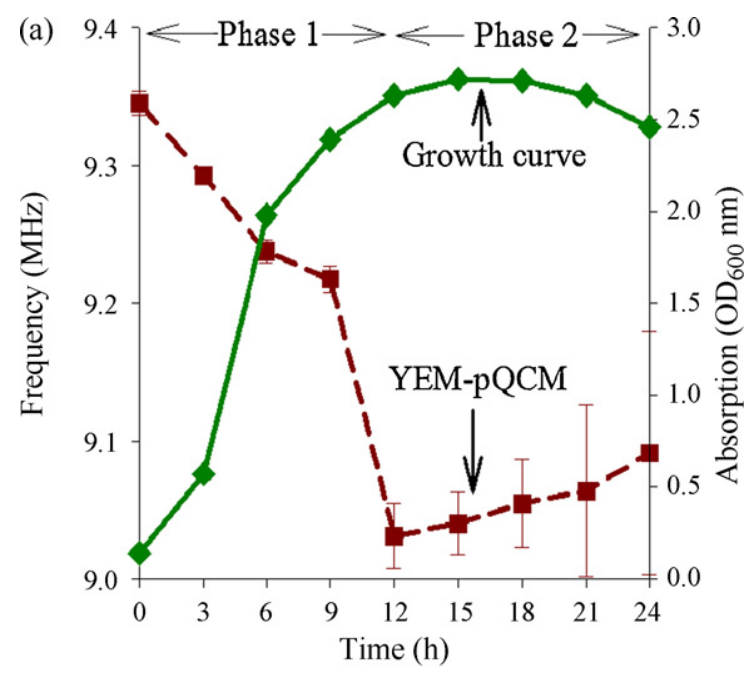

(left $\bullet$ ): YEM-pQCM, (right $\diamond$ ): Growth curve

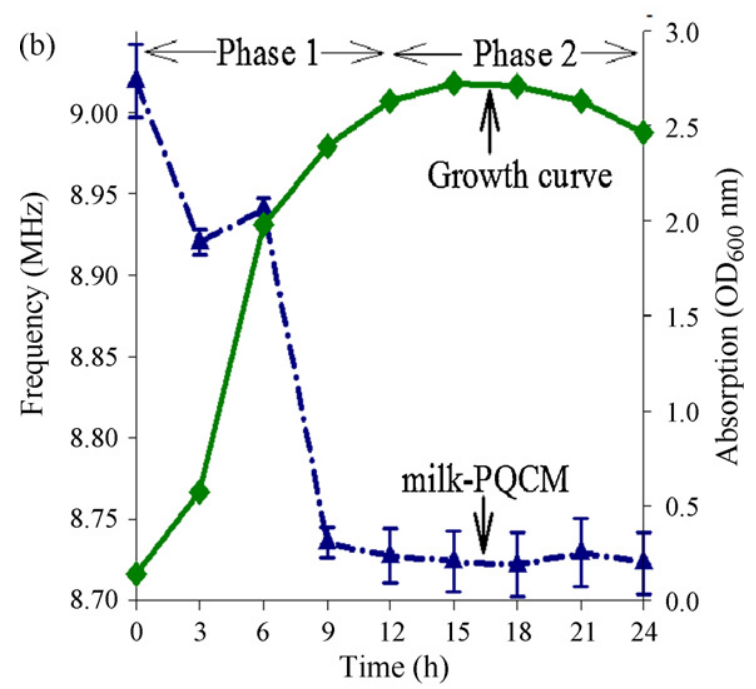

(left $\bullet$ ):milk-PQCM, (right $\bullet$ ):Growth curve

Fig. 2. Real-time response of resonance frequency of $p Q C M$ sensor to $E$. coli frequency shift of (a) YEM bacterial solution samples and (b) milk bacteria solution samples. The growth curve $\left(\mathrm{OD}_{600}\right)$ is divided into two phases and is used as a control parameter. tion, expressed in terms of the absorbance value $\left(\mathrm{Abs}_{600}\right)$, is used as a control parameter.

As shown in Fig. 2a, the growth curve is divided into two phases. In the first phase, the cell concentration increases rapidly from $\mathrm{Abs}_{600} 0$ to $\mathrm{Abs}_{600} 2.5$ in $0-12 \mathrm{~h}$; then, it steadily increases to $\mathrm{Abs}_{600}$ $\sim 2.7$, followed by a steady decrease to $\mathrm{Abs}_{600} \sim 2.5$; this trend implies a typical cell proliferation. In the YEM bacterial medium sets, the frequency shifts decrease dramatically during the first $12 \mathrm{~h}$ to a value of $\sim 0.3 \mathrm{MHz}$, and the frequency response profiles reflect the course of bacterial growth. We find that the decrease in the magnitude of the resonance frequency corresponds to the bacterium verification, which is supposed to be attributed to the cell growth and the deposition of a few cells onto the $p Q C M$ surface (first phase).During the next $12-24 \mathrm{~h}$ (second phase), the frequency steadily increases to approximately $0.03 \mathrm{MHz}$.

This steady state of the bacterium growth slows down with the consumption of nutrients, and cells are attached to the sensor surface as shown in Fig. 1a. The proliferation of $E$. coli adhered to the sensor surface and the increase in the resonance frequency are proportional to the values of the $E$. coli bulk and surface concentrations.

In the milk bacterial medium sets shown in Fig. 2b, we are unable to measure the growth curve of the E. coli concentration by detecting shifts in the $\mathrm{Abs}_{600}$ value due to the opaqueness of the milk as unsuitable for spectroscope analysis; therefore, we used the YEM bacterial growth curve as a control parameter. In the first phase of the experiments using the milk sample, the frequency shifts decrease to a value of $\sim 0.25 \mathrm{MHz}$, and the obtained response profiles are similar to those of the YEM experiments during the second phase; then, the frequency shift stabilizes.

\subsection{Cooperation of medium}

Generally, uncharged or weakly charged substrates are transformed into strongly charged substrates produced by bacteria; bacteria may secrete secondary metabolites that cause a change in $\mathrm{pH}$ values, inducing conductivity changes (Cai and Grimes, 2000). This was shown by Zhao et al. (2005) using a bulk acoustic wave impedance biosensor for E. coli detection.

Fig. 3 shows the shifts in the $\mathrm{pH}$ value of the medium, which is related to bacterial population. When $E$. coli is inoculated in the medium, the $\mathrm{pH}$ value in the YEM bacterial solution decreases and reflects the growth in the bacterial population; the $\mathrm{pH}$ value is in the range $7-4.7$. However, the $\mathrm{pH}$ value does not change significantly in the experiments on milk samples; in this case, the $\mathrm{pH}$ value of the medium is $\sim 6.5$. A comparison with the $E$. coli growth curve shown in Fig. 1 shows that the bacterial population causes frequency shifts of the $p Q C M$ sensor. The trend of changes in the $\mathrm{pH}$ values in the experiments on the YEM and milk samples indicates that the $\mathrm{pH}$ value is not a function of the frequency shifts of the $p Q C M$ sensors. When the $\mathrm{pH}$ value increases from 4 to 7 , the frequency shifts of the $p Q C M$ decreases to $500 \mathrm{~Hz}$, which is significantly lower than the frequency shift of $300 \mathrm{kHz}$ caused by E. coli growth. A considerable difference is observed between the growth rates in the YEM nutrient medium and milk because different mediums (with different compositions) would induce different growth behaviors of a bacterial population. The composition of milk is more complicated than that of the YEM medium, and the changes in $\mathrm{pH}$ when the medium is milk are fairly moderate.

Impedance is defined as the resistance to the flow of an alternating current as it passes through a conducting material. The secretion of metabolites by microbes results in a decrease in the impedance, which also causes nutrients to hydrolyze to a small electrolyte.

The medium conductivity is shown in Fig. 4. The changes in the medium conductivity in the experiments performed on YEM and milk samples are related to the bacterial population. When 


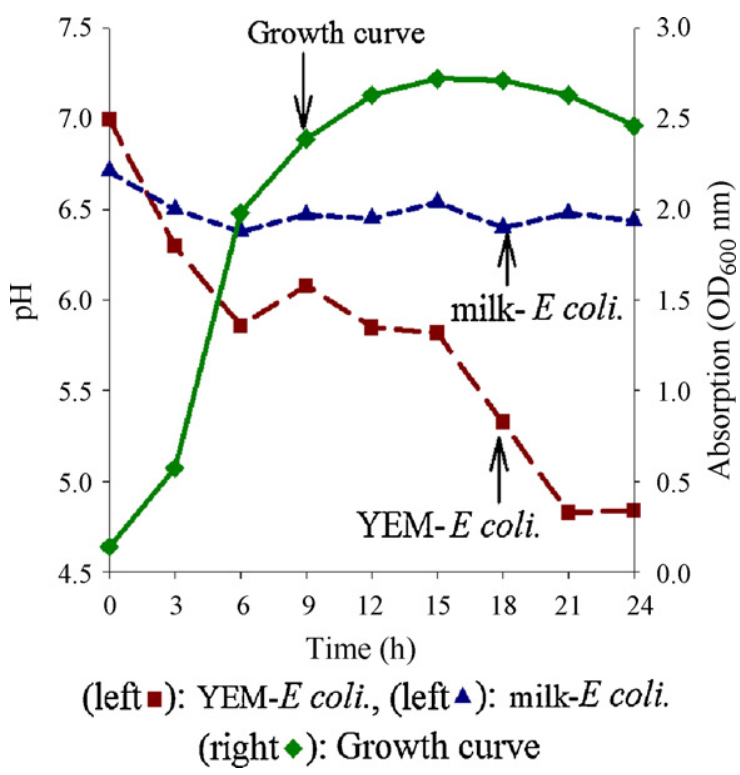

Fig. 3. Shifts in $\mathrm{pH}$ value of YEM and milk samples as a function of $E$. coli concentration in culture medium over a period of time. Milk samples show a steady $\mathrm{pH}$ variation and YEM samples show a decrease in the $\mathrm{pH}$ values, related to the cultivation time. The growth curve shown in Fig. 2 is used as the control.

E. coli cells are seeded to a medium, we obtain the opposite results-an increase in the conductivity of the bacterial solution to $2.1-3 \mathrm{mS} \mathrm{cm}^{-1}$ in the YEM sample experiments, and a decrease in the conductivity of the bacterial solution to $5.0-4.3 \mathrm{mS} \mathrm{cm}^{-1}$ in the milk sample experiments. A comparison with the $E$. coli growth curve shown in Fig. 1 shows that the bacterial population causes frequency shifts of the $p Q C M$ sensor; the changes in the frequency shifts are not dependent on the electrolyte medium. When the conductivity value verifies from 5.0 to $4.3 \mathrm{mS} \mathrm{cm}^{-1}$ (milk) and 2.1 to $3 \mathrm{mS} \mathrm{cm}^{-1}$ (YEM medium), the frequency shifts of $p \mathrm{QCM}$ of $300 \mathrm{kHz}$ caused by them are produced. It is significantly higher than the frequency shift of $100 \mathrm{~Hz}$ with the variation of $2-5 \mathrm{mS} \mathrm{cm}^{-1}$ (phosphate buffer dilution) in the reference conductivity experiment.

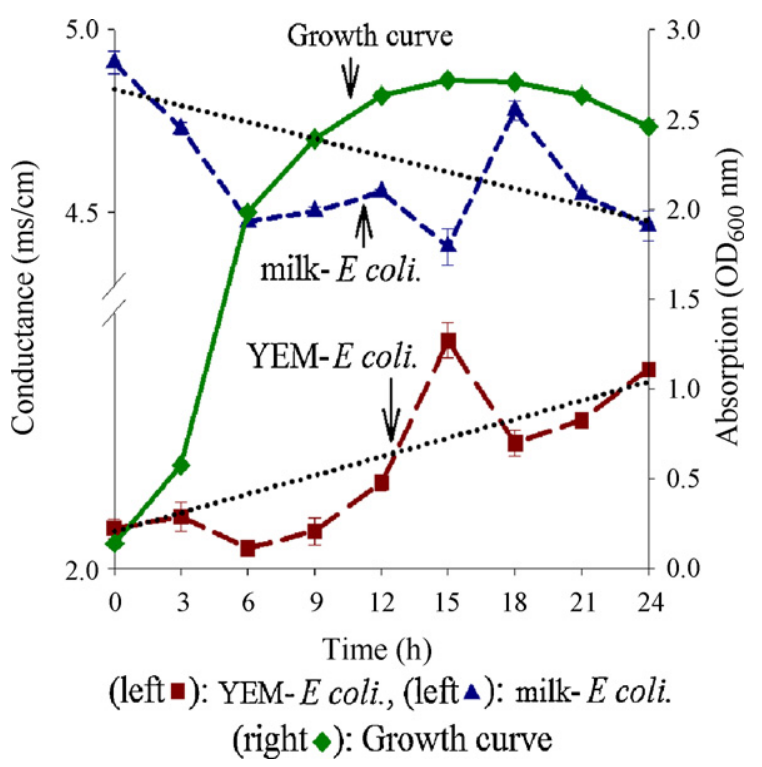

Fig. 4. Shifts in conductivity of bacterial solution of YEM sample and milk sample. The conductivities of the YEM and milk samples increased and decreased, respectively. The growth curve was used as the control.
Both experiments on the conductivity of the bacterial medium show trends similar to those obtained in the experiment results of the same nutrient medium when a good control is achieved.

Furthermore, we have measured shifts in the medium viscosity in YEM and milk samples; the results of the measurements are shown in Fig. 5. The changes in both medium viscosities, induced by the bacterial population, are calibrated with glycerol-water mixtures for achieving control, and the results are shown later. The changes in the bacterial medium viscosity are related to the proliferation of $E$. coli, as shown in Fig. 6. In the YEM bacterial medium viscosity increases after incubation for $0-6 \mathrm{~h}$; viscosity increases in the range $3.2-4.7 \mathrm{cps}$, and decreases to $4.7-3.2$ after $6-9 \mathrm{~h}$; then, the value stabilizes after $12 \mathrm{~h}$. The correlation of the trend of the change in the viscosity with the $p \mathrm{QCM}$ frequency is opposite to the bacterial growth curve shown in Fig. 1 for $0-6 \mathrm{~h}$; the trend of the change in the YEM bacterial medium viscosity is related to the $E$. coli growth curve (after $6 \mathrm{~h}$ ) shown in Fig. 1 . The trend of the changes in the bacterial medium viscosity in the milk sample experiments is very similar to that in the YEM sample experiments. The YEM medium viscosity increases $0-6 \mathrm{~h}$ after incubation, and its value becomes 4.3-5.5 cps; then, the value decreases to 5.5-3.9 cps after $6-9 \mathrm{~h}$ and the value increases steadily after $12 \mathrm{~h}$. Using a viscometer and the $p Q C M$, we have calibrated the medium-viscosity-induced frequency shifts of the $p \mathrm{QCM}$; glycerol-water mixtures of known density and viscosity are used as controls.

Fig. 6a shows the excitation of the resonator signal due to different concentrations of the glycerol-water mixtures, where the content of glycerol in deionized water was between $0 \%$ and $20 \%$.

The $p \mathrm{QCM}$ sensor is able to detect $1 \%$ glycerol with a frequency shift of $\sim 47 \mathrm{~Hz}$. A satisfactory correlation $\left(r^{2}=0.9362\right)$ is obtained between the concentration of the glycerol-water mixture and the response of the $p \mathrm{QCM}$ sensor. Furthermore, the viscosity shift in this case is $\sim 0.194 \mathrm{cps}$. A satisfactory correlation $\left(r^{2}=0.9318\right)$ was obtained between the concentration of the glycerol-water mixture and the response of the viscometer. In this case, the change in the medium viscosity by $1 \mathrm{cps}$ is equivalent to the value of the frequency shift of the $p Q C M$, approximately $100 \mathrm{~Hz}$.

A comparison of these results with the changes in the viscosity of the E. coli growth medium is shown in Fig. 5, when the vis-

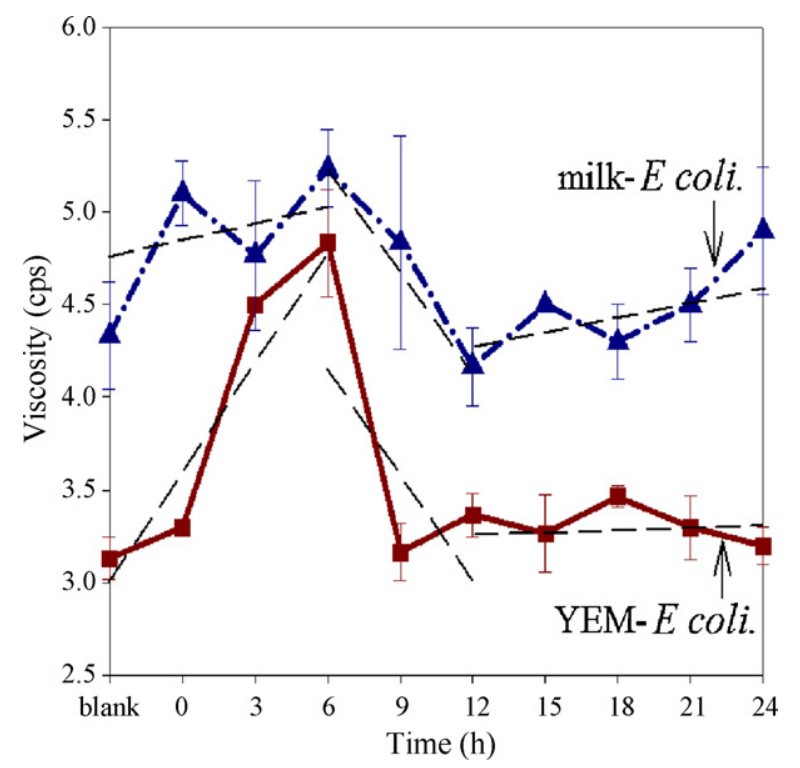

Fig. 5. Changes in viscosity values of YEM and milk samples. For a given culture time, the results showed no significant difference in the trend of changes in viscosity. Additionally, the viscosity increased when inoculation was carried out, followed by a decrease. 
cosity value verifies from 3.2 to $4.7 \mathrm{cps}$ (YEM medium) and 4.3 to $5.5 \mathrm{cps}$ (milk), the frequency shifts of $p \mathrm{QCM}$ caused by bacterial proliferation decreases to $300 \mathrm{kHz}$. It is significantly higher than the frequency shift of approximately $150 \mathrm{~Hz}$ with the variation of 3.2-4.7 cps and $120 \mathrm{~Hz}$ and with the variation of $4.3-5.5 \mathrm{cps}$ in glycerol-water mixtures in the reference viscosity experiment.

\subsection{Reusability of $p Q C M$ sensor}

The $p \mathrm{QCM}$ sensor reusability is shown in Fig. 6b. Experiments have been performed by constructing three-pQCM flasks-containing three- $p \mathrm{QCM}$ devices that have a similar mass loading effect in the YEM medium and the same seeding concentration of $E$. coli. After cultivation for $18 \mathrm{~h}$, the frequency changes

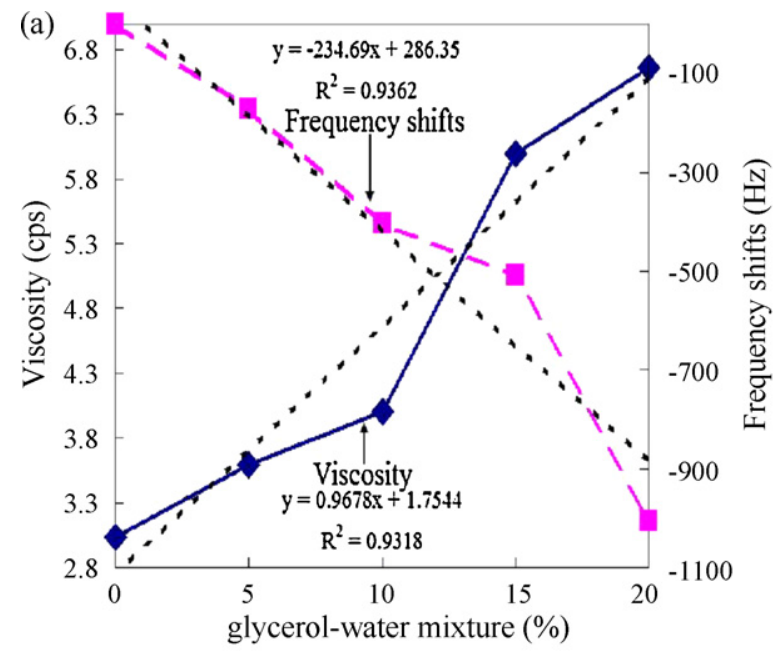

\section{(left): Viscosity, (right»): Frequency shifts}

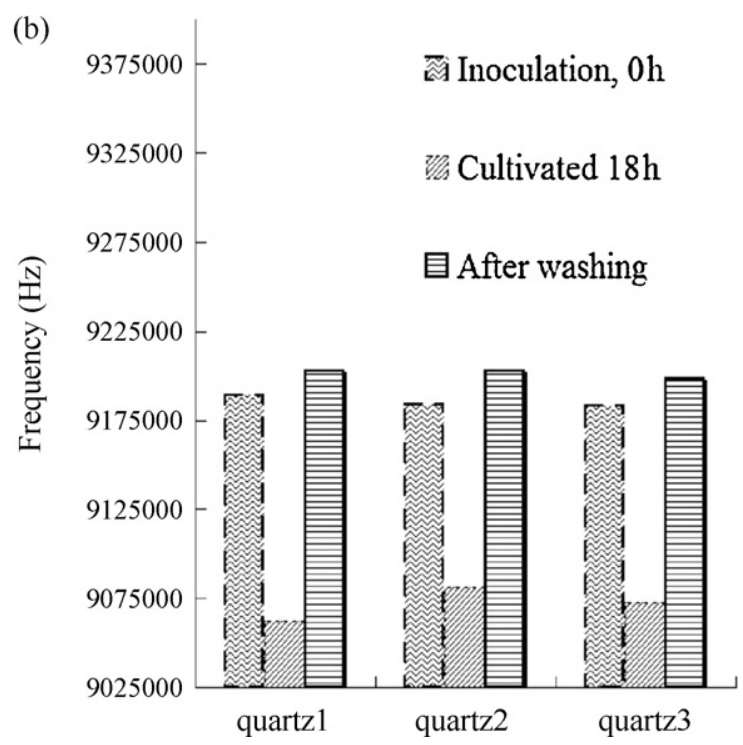

Fig. 6. (a) Viscosity changes and frequency shifts of glycerol-water mixture. The pQCM device was immersed into mixtures with glycol concentrations of $0 \%, 5 \%, 10 \%$, $15 \%$, and $20 \%$. The frequency changes induced by small molecules (glycerol-water) were significantly lower than those induced by bacterial proliferation. (b) $p Q C M$ sensor reusability. Three different $p Q C M$ devices were inoculated, cultivated for $18 \mathrm{~h}$, and then washed. These results show that the fundamental frequencies decrease after $18 \mathrm{~h}$ of cultivation; however, the devices can be reused after washing and sterilization. are measured, and the apparatus are gently rinsed with deionized water. The absolute value of the central frequency obtained by comparing the central frequencies before cultivation and after the rinsing is $\sim 0.01 \mathrm{MHz}$, which is equal to the surface and bulk concentrations of $E$. coli. All three $p Q C M s$ that are inoculated and cultured for over $18 \mathrm{~h}$ show changes in their central frequency, whose value becomes $0.1 \mathrm{MHz}$. The changes are induced by the bacterial population growth and are dependent on the concentration of inoculated $E$. coli cells. The results show that the washing of the three $p Q C M s$ with deionized water would result in a similar central frequency. The results show the good reusability of the pQCM that has similar frequency changes.

\section{Conclusion}

This work has demonstrated the potential of the $p Q C M$ in the monitoring of a bacterial population. The $p \mathrm{QCM}$ can be used to determine the factors that cause frequency changes such as mass loading, conductivity, and viscosity. The experimental results show that mass loading is the main factor that causes frequency shifts in the $p Q C M$. The $p Q C M$ provides a sensitivity of approximately $14 \mathrm{~Hz} / \mathrm{mm}^{2} \mathrm{ng}^{-1}$ in liquid $\left(r^{2}=0.964\right), 4 \mathrm{~Hz} / \mathrm{mm}^{2} \mathrm{ng}^{-1}$ in air $\left(r^{2}=0.978\right)$, and a detection limit of $10^{2}$ cells $\mathrm{ml}^{-1}$ of $E$. coli $\left(r^{2}=0.9979\right)$. The $p Q C M$ sensor can analyze microbial population directly in the culture broth and does not induce any risk posed by toxins produced due to surface modification. Besides, the $p \mathrm{QCM}$ has good stability with a frequency drift of $170 \mathrm{~Hz}$ after $10 \mathrm{~h}$ under liquid conditions. The results of reusability experiments show that just a gentle rinse would remove the $E$. coli from the surface, followed by a sterilization of the $p Q C M$ by $70 \%$ ethanol for the next use.

\section{References}

Alessandrini, A., Croce, M.A., Tiozzo, R., Facci, P., 2006. Appl. Phys. Lett. 88, 083905. Ben-Dov, I., Willmer, I., Zisman, E., 1997. Anal. Chem. 69, 3506-3512. Cavic, B.A., Hayward, G.L., Thompson, M., 1999. Analyst 124, 1405-1420.

Cai, Q.Y., Grimes, C.A., 2000. Sens. Actuators B 71, 112-117.

Chang, K.-S., Hsu, W.-L., Chen, H.-Y., Chang, C.-K., Chen, C.-Y., 2003. Anal. Chim. Acta 481, 199-208.

Cho, N.-J., Cheong, K.H., Lee, C.H., Frank, C.W., Otzen, J.S., Besenbacher, F., 2007. Biophys. J. 93, 2162-2169.

Chou, S.-F., Hsu, W.-L., Hwang, J.-M., Chen, C.-Y., 2002a. Anal. Chim. Acta 453 (2), 181-189.

Chou, S.F., Hsu, W.-L., Hwang, C.-M., Chen, C.-Y., 2002b. Clin. Chem. 48 (6), 913-918. Cooper, M.A., Singleton, V.T., 2003. J. Mol. Recognition 20 (3), 154-184.

De Mol, R.M., Ouweltjes, W., 2000. Proceedings of Robotic Milking, Lelystad, The Netherlands. Wageningen Press, The Netherlands, pp. 97-107.

Fengjiao, H., Qing, G., Wenghong, Z., Lihua, N., Shouzhuo, Y., Chang, M., 1994. Anal. Chim. Acta 289, 313-319.

Hillerton, J.E., Walton, A.W., 1991. Vet. Rec. 128, 513-515

Hovgaard, M.B., Dong, M., Otzen, D.E., Besenbacher, F., 2007. Biophys. J. 93, 2162-2169.

Kim, N., Park, I.S., Kim, D.K., 2004. Sens. Actuators B 100, 432-438.

Kosorok, M.R., Jalaluddin, M., Farrell, P.M., Shen, G., Colby, C.E., Laxova, A., Rock, M.J., Splaingard, M., 1998. Pediatr. Pulmonol. 26, 81-88.

Louis, D., Sorlier, P., Wallach, J., 1998. Clin. Chem. Lab. Med. 36, 295-298.

Miller, G.Y., Bartlett, P.C., Lane, S.E., Anderson, J., Heider, L.E., 1993. J. Am. Vet. Med. Assoc. 202, 1230-1236.

Mullett, W.M., Lai, E.P., Yeung, J.M., 2000. Methods 22 (1), 77-91.

Milner, P., Page, K.L., Walton, A.W., Hillerton, J.E., 1996. J. Dairy Sci. 79, 83-86.

Noel, M.A.M., Topart, P.A., 1994. Gen. Considerations Anal. Chem. 66 484-491.

Oberst, R.D., Hays, M.P., Bohra, L.K., Phebus, R.K., Yamashiro, C.T., Paszko-Kolva C., Flood, S.J., Sargeant, J.M., Gillespie, J.R., 1998. Appl. Environ. Microb. 64 3389-3396.

Oliver, S.P., Murinda, S.E., Almeida, R.A., 2003. The University of Tennessee, Knoxville http://animalscience.ag.utk.edu/pdf/Reports/Oliver Mastitis\%20Control \%20Food\%20Safety\%20\&\%20Quality\%20Milk.pdf.

Park, I.-S., Kim, W.-Y., Kim, N., 2000. Biosens. Bioelectron. 15, 167-172.

Sauerbrey, G.Z., 1959. Physics 155, 206.

Shankaran, D.R., Gobi, K.V., Miura, N., 2007. Sens. Actuators B 121, 158-177. 
Sharma, V.K., Dean-Nystrom, E.A., Casey, T.A., 1999. Mol. Cell. Probes 13, 291-302.

Spangler, B.D., Tyler, B.J., 1999. Anal. Chim. Acta 399, 51-62.

Spangler, B.D., Wilkinson, E.A., Murphy, J.T., Tyler, B.J., 2001. Anal. Chim. Acta 444, 149-161.

Toby, M., Alisa, R., Andrey, L., Julie, L.F., P. David, E., 2007. Biosens. Bioelectron. 22, 2689-2693.
Weast, R.C. (Ed.), 1984. Handbook of Physics and Chemistry. CRC Press, Boca Raton, FL.

Xu, J., Moore, J.E., Murphy, P.G., Millar, B.C., Elborn, J.S., 2004. Ann. Clin. Microbiol. Antimicrob. 3, 21.

Zhao, J.W., Zhu, W.J., He, F.J., 2005. Sens. Actuators B 107, 271-276. 